\title{
Interaction of ketoprofen and frusemide in man
}

\author{
T.C. Li Kam Wa*, M. Lawson, S.H.D. Jackson**, A. Hitoglou-Makedou and \\ P. Turner
}

Department of Clinical Pharmacology, St. Bartholomew's Hospital, West Smithfield, London EC1A $7 B E$, $U K$

\begin{abstract}
Summary: The effects of ketoprofen on frusemide-induced diuresis, natriuresis and renin release were studied in 12 healthy male volunteers. Each received frusemide $\mathbf{4 0} \mathrm{mg}$ once daily with either ketoprofen $100 \mathrm{mg}$ twice daily or placebo for two periods of 5 days separated by a treatment-free period according to a randomized, double-blind, cross-over study design. Ketoprofen significantly reduced frusemide-induced diuresis on Day 1 but not on Day 5 of treatment. The natriuresis induced by frusemide on Day 1 or Day 5 of treatment did not differ significantly whether ketoprofen or placebo was administered, although the mean urinary sodium excretion values were consistently lower following ketoprofen. Ketoprofen did not affect the kaliuretic response to frusemide on Day 1 or Day 5 of treatment. The increase in plasma renin activity after frusemide was inhibited by ketoprofen on both Day 1 and Day 5 . These results suggest that ketoprofen reduces the diuresis and renin release induced by frusemide, but that the reduction in diuretic response may become less important after their repeated coadministration.
\end{abstract}

\section{Introduction}

Conflicting results have been obtained with respect to the effects of nonsteroidal anti-inflammatory drugs (NSAIDs) on frusemide-induced diuresis and natriuresis, with a blunting ${ }^{1-4}$ or no change ${ }^{5-7}$ being reported. NSAIDs inhibit the early increase in plasma renin activity (PRA) which follows frusemide administration. ${ }^{1-3,6,7}$ Ketoprofen is a propionic acid derivative which has been shown to be safe and effective in the symptomatic treatment of rheumatoid and osteoarthritic diseases. ${ }^{8,9}$ There is no information available on the interaction of ketoprofen with frusemide. The absence of an interaction would make ketoprofen a NSAID of first choice when coadministration with frusemide is necessary.

This study was designed to investigate the effects of ketoprofen on frusemide-induced diuresis, natriuresis, and renin release following single and multiple doses of both drugs in healthy volunteers.

Correspondence: Professor P. Turner, B.Sc., M.D., F.R.C.P

*Present address: Clinical Pharmacology Unit, Department of Medicine, The Royal Infirmary, Edinburgh EH3 9YW, UK

**Present address: Department of Health Care of the Elderly, King's College School of Medicine and Dentistry, London SE5, UK

Accepted: 14 January 1991

\section{Methods}

Twelve healthy male volunteers, aged $20-34$ years (mean age 24 ) and within $10 \%$ of their ideal body weight, gave informed written consent to the study which was approved by the Ethical Committee of the City and Hackney District Health Authority. They were non-smokers and drank no alcohol during the trial periods. They were on no medication for at least one week prior to the start of the study and only the study medications were allowed during the study.

Each subject was randomly allocated to receive frusemide (40 mg once daily) together with either ketoprofen (100 mg capsule twice daily) or a matching placebo for 5 days according to a doubleblind, cross-over design, the two treatment periods being separated by 9 days. Dietary advice was given in an attempt to moderate their intake of foods high in sodium and potassium for 5 days prior to and during the whole of each treatment period. Water intake was not limited but they were instructed to drink at least 2 litres of fluid daily. Twenty-four hour urine collections were made just before the start of each treatment period to assess sodium and potassium excretion and thus the approximate dietary intake of sodium and potassium of the volunteers.

The subjects attended on the mornings of Day 1 and Day 5 of each treatment period after fasting from $22.00 \mathrm{~h}$ the previous evening. A standard light breakfast without caffeine was taken. They 
assumed a supine position for 30 minutes after which a blood sample was drawn for measurement of PRA. After emptying their bladders, they took frusemide and either ketoprofen or placebo with $100 \mathrm{ml}$ water. Following this, they drank $100 \mathrm{ml}$ water hourly for the next 5 hours. Another blood sample for PRA was taken at 1 hour post-dosing, after a 30 minute period of supine rest. Hourly total urine collections were made during the first 6 hours after dosing. The subjects were then allowed home to complete their 24 hour urine collections.

Urine volumes were recorded and $10 \mathrm{ml}$ aliquots stored at $-20^{\circ} \mathrm{C}$ until analysis for sodium and potassium. Blood samples for measurement of PRA were collected into tubes containing sodium ethylenediamine tetra-acetate (EDTA) and kept on ice. After centrifugation at $4^{\circ} \mathrm{C}$, the plasma was
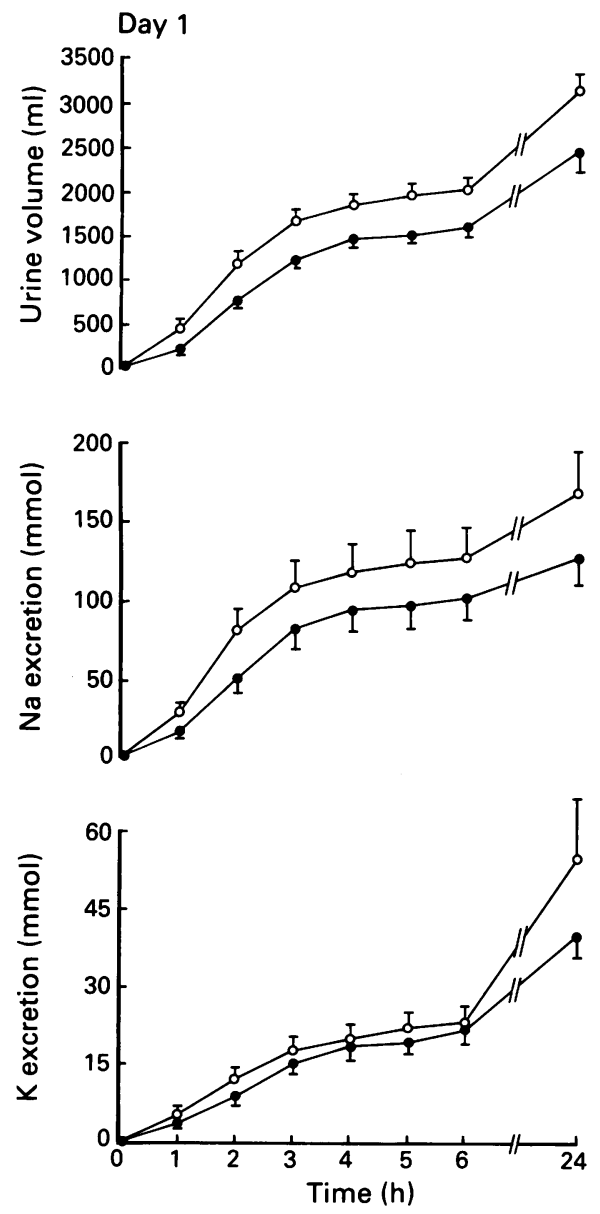

Figure 1 Cumulative urinary volume $(\mathrm{ml})$, sodium and potassium excretion (mmol) following administration of frusemide $40 \mathrm{mg}$ with either placebo (-O-) or ketoprofen $100 \mathrm{mg}$ (- - ) on Day 1 of the treatment period. Each point represents the mean value ( \pm s.e.m.) of 12 subjects.

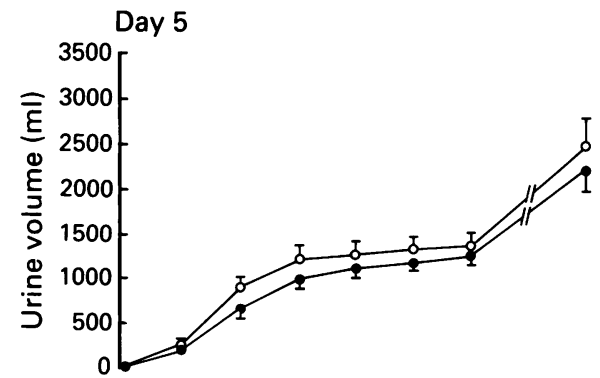

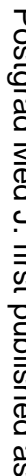
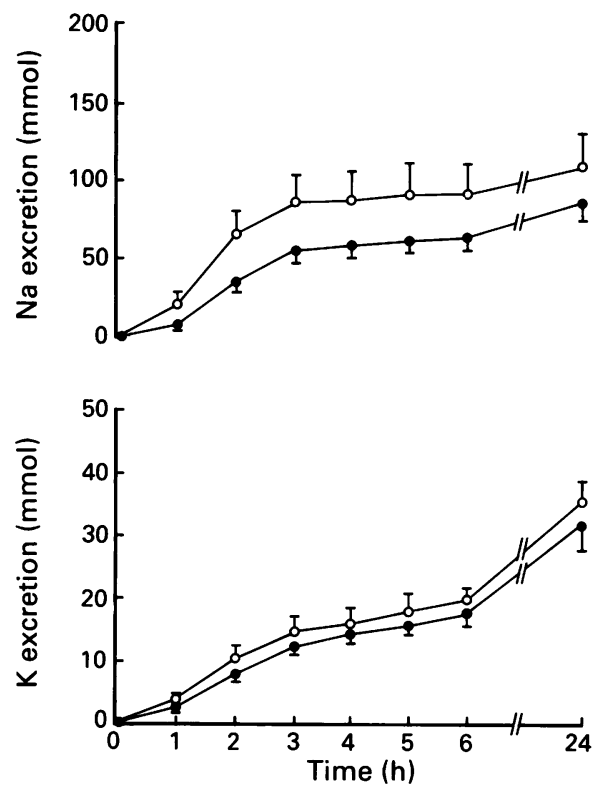

Figure 2 Cumulative urinary volume $(\mathrm{ml})$, sodium and potassium excretion ( $\mathrm{mmol}$ ) following administration of frusemide $40 \mathrm{mg}$ with either placebo (-O-) or ketoprofen $100 \mathrm{mg} \mathrm{(-O)} \mathrm{on} \mathrm{Day} 5$ of the treatment period. Each point represents the mean value $( \pm$ s.e.m.) of 12 subjects.

separated immediately and stored at $-20^{\circ} \mathrm{C}$ until analysis. PRA was measured by radioimmunoassay of angiotensin I (AI) generated under standard conditions and was expressed as pmol of angiotensin I generated $\mathrm{h}^{-1} \mathrm{l}^{-1}$ of plasma at $\mathrm{pH} 7$ and at $37^{\circ} \mathrm{C}$. Urinary sodium and potassium concentrations were analysed by automated flame photometry.

The hourly total urine volumes, sodium and potassium excretion in the first 6 hours after drug administration were analysed using multiple linear regression analysis with treatment, time or measurement and subjects included as independent variables, employing the dummy variable technique. Student's paired $t$ test was used to examine the treatment effect on PRA, 24 hour urine volumes, sodium and potassium excretion. 

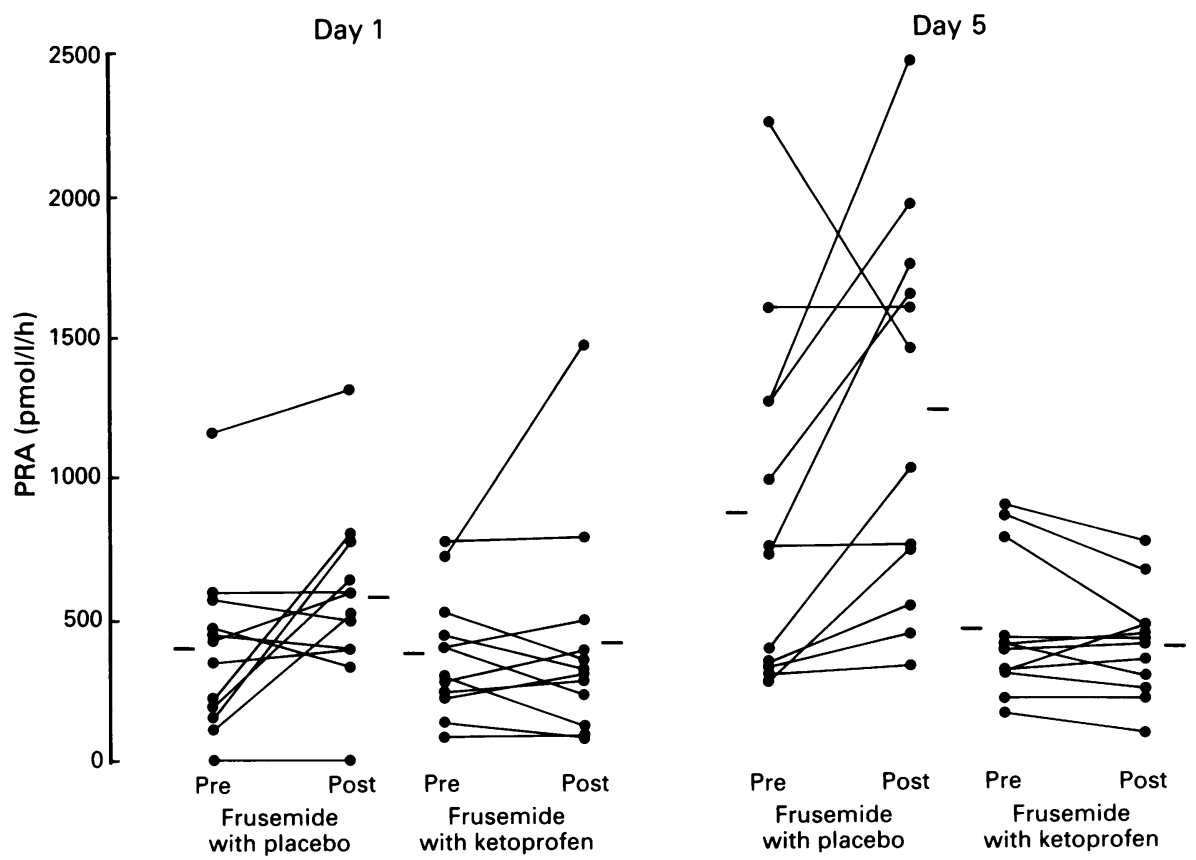

Figure 3 Plasma renin activity (PRA pmol AI/l/h) before and after administration of frusemide $40 \mathrm{mg}$ in the presence of placebo or ketoprofen $100 \mathrm{mg}$. The horizontal bars indicate the mean values of the 12 subjects.

\section{Results}

Twenty-four hour sodium excretion values on the day prior to each treatment period were similar: $113 \pm 93 \mathrm{mmol}$ (mean \pm s.d.) prior to placebo and $117 \pm 79 \mathrm{mmol}$ prior to ketoprofen. The potassium excretion values were $38 \pm 14$ and $50 \pm 26 \mathrm{mmol}$ respectively. These differences were not significant.

Ketoprofen, when compared with placebo, significantly reduced frusemide-induced diuresis over the 6 hours after drug administration (mean difference $=-67 \mathrm{ml}, P<0.05$ ) and the 24 hour urine output (mean difference $=-651 \mathrm{ml}, P<0.05$ ) on Day 1 (Figure 1). On Day 5 of treatment (Figure 2), the changes did not reach significance.

The natriuresis induced by frusemide on Day 1 or Day 5 of treatment did not differ significantly whether ketoprofen or placebo was administered, although the mean urinary sodium excretion values were consistently lower following ketoprofen (Figures 1 and 2).

Similar changes were seen for frusemide-induced kaliuresis although the magnitude of the mean differences was much smaller (Figures 1 and 2).

Frusemide, when administered with placebo, significantly increased PRA over basal values on both Day 1 (mean difference $=183 \mathrm{pmol} / \mathrm{l} / \mathrm{h}, P<$ 0.05 ) and Day 5 (mean difference $=355 \mathrm{pmol} / \mathrm{l} / \mathrm{h}$, $P<0.01)$ of the treatment period. Ketoprofen abolished this frusemide-induced rise in PRA on both days (Figure 3 ).

\section{Discussion}

The results of this study demonstrated that ketoprofen suppressed frusemide-induced diuresis and increase in PRA following concomitant administration of single doses of both drugs. On Day 5 of treatment, however, ketoprofen had no significant effect on diuresis while PRA remained suppressed. Ketoprofen did not have a significant effect on the natriuretic response although the mean urinary excretion values were consistently lower when ketoprofen was administered. These results were obtained with doses and route of administration of frusemide and ketoprofen which are commonly used in every day clinical practice. We chose to study for any interaction after both drugs were administered simultaneously because patients commonly take their medication together and the times to peak concentration of the drugs were comparable. ${ }^{10,11}$

The interference by NSAIDs with the diuresis and natriuresis induced by frusemide has previously been demonstrated by others ${ }^{1-4}$ and is believed to be due to inhibition of renal prostaglandins by NSAIDs. However, other investigators 
have demonstrated no interference with these actions of frusemide. ${ }^{5-7}$ The reasons for the disparity in results between these studies are unclear and may be partly due to difference in trial design, route of frusemide administration, specific NSAID employed, salt intake of the subjects, duration of treatment and dosage used. It is also possible that the natriuresis following frusemide is not entirely prostaglandin-dependent and that other prostaglandin-independent mechanisms may be responsible for the interaction of NSAIDs on frusemideinduced diuresis and natriuresis. ${ }^{7}$ Our finding of a greater effect following acute than chronic administration of frusemide and ketoprofen also suggests that inhibition of prostaglandin inhibition may not be the only mechanism involved in this interaction, since one would expect a greater effect on prostaglandin inhibition with repeated administration of ketoprofen. Whatever the mechanisms involved, the results obtained in this study, using doses which represent commonly prescribed treatment regimens for both drugs, indicate that this interaction may be less important on longer term dosing.

A biphasic renin response is described with loop diuretics. There is an early stimulation, mostly observed after intravenous administration, which is thought to be a prostaglandin-mediated event, followed by a late rise which is due to salt and water depletion. The early increase in PRA after frusemide is consistently blocked by NSAIDs ${ }^{1-3,6,7}$ and our results are in accordance with these studies. The suppression of frusemide-stimulated renin release by ketoprofen in the absence of a significant effect on natriuresis is in keeping with the findings of other investigators that sodium retention and presumed consequent volume expansion is not the mechanism for renin suppression of NSAIDs. ${ }^{1,2,6,7}$

We conclude that ketoprofen interferes with the diuresis and renin release induced by frusemide but the interference with the diuretic response of frusemide may become less important after repeated coadministration of both drugs. The absence of such an effect by a useful analgesic drug may be a potentially valuable property in clinical situations requiring both drugs. From these data, it cannot, however, be predicted whether similar results will be obtained in patients.

\section{Acknowledgements}

We thank Rhone Poulenc for financial assistance and supplying the study medications.

\section{References}

1. Patak, R.V., Mookerjee, B.K., Bentzel, C.J., Hysert, P.E., Babej, M. \& Lee, J.B. Antagonism of the effects of furosemide by indomethacin in normal and hypertensive man. Prostaglandins 1975, 10: 649-659.

2. Frolich, J.C., Hollifield, J.W., Dormois, J.C. et al. Suppression of plasma renin activity by indomethacin in man. Circ Res 1976, 39: 447-452.

3. Mackay, I.G., Muir, A.L. \& Watson, M.L. Contribution of prostaglandins to the systemic and renal vascular response to frusemide in normal man. Br J Clin Pharmacol 1984, 17: 513-519.

4. Hitoglou-Makedou, A., Lawson, M., Turner, P. \& Ferber, H.P. Comparison of chlortenoxicam and indomethacin on frusemide-induced diuresis. Postgrad Med J 1989, 65: 821-823.

5. Berg, K.J. Acute effects of acetylsalicylic acid on renal function in normal man. Eur J Clin Pharmacol 1977, 11: 117-123.

6. Weber, P.C., Scherer, B. \& Larsson, C. Increase of free arachidonic acid by furosemide in man as the cause of prostaglandin and renin release. Eur J Pharmacol 1977, 41: 329-332.

7. Riley, L.J., Vlasses, P.H., Rotmensch, H.H. et al. Sulindac and ibuprofen inhibit furosemide-stimulated renin release but not natriuresis in men on a normal sodium diet. Nephron 1985, 41: 283-288.

8. Gyory, A.N., Bloch, M., Burry, H.C. \& Grahame, R. Orudis in the management of rheumatoid arthritis and osteoarthritis of the hip: comparison with indomethacin. Br Med J 1972, 4: 398-400.

9. Zutshi, D.W., Stern, D., Bloch, M. \& Mason, R.M. Ketoprofen: double-blind cross-over study with indomethacin in patients with rheumatoid arthritis. Rheumatol Rehabil 1974 13: $10-16$

10. Boles Ponto, L.L. \& Schoenwald, R.D. Furosemide (Frusemide). A pharmacokinetic/pharmacodynamic review. Clin Pharamcokinet 1990, 18: 381-408.

11. Upton, R.A., Williams, R.L., Guentert, T.W., Buskin, J.N. \& Riegelman, S. Ketoprofen pharmacokinetics and bioavailability based on an improved sensitive and specific assay. Eur J Clin Pharmacol 1981, 20: 127-133. 